\title{
Assessment of firefighters' occupational exposure to polycyclic aromatic hydrocarbons by biomonitoring
}

\author{
Marta Oliveira ${ }^{1}$, Klara Slezakova², João Paulo Teixeira ${ }^{3}$, Adília Fernandes ${ }^{4}$, Maria
}

Carmo Pereira ${ }^{5}$, Simone Morais ${ }^{6}$

${ }^{1}$ REQUIMTE-LAQV, School of Engineering, Polytechnic of Porto, PT (Marta.Oliveira@graq.isep.ipp.pt) ORCID 0000-0003-4150-0151, 2LEPABE, Faculty of Engineering, University of Porto, PT (slezakok@fe.up.pt) ORCID 0000-0001-5265-4186, ${ }^{3}$ EPIUnit, Institute of Public Health, University of Porto, PT (jpft12@gmail.com), ${ }^{4}$ Polytechnic Institute of Bragança, PT (adilia@ipb.pt) ORCID 0000-0003-1658-4509, ${ }^{5}$ LEPABE, Faculty of Engineering, University of Porto, PT (mcsp@fe.up.pt) ORCID 0000-0001-8505-3432, 6REQUIMTE-LAQV, School of Engineering, Polytechnic of Porto, PT (sbm@isep.ipp.pt) ORCID 0000-0001-6433-5801

https://doi.org/10.24840/978-972-752-260-6_0018-0021

\begin{abstract}
Introduction: Firefighters may suffer potential health risks due to the regular exposure to polycyclic aromatic hydrocarbons (PAHs) emitted from forest fires. This work determines the concentrations of the biomarker of exposure of PAHs, 1-hydroxypyrene, in the urine of firefighters recently exposed to fire emissions. Methodology: Urinary 1-hydroxypyrene was determined by solid-phase exctration followed by a liquid chromatographic analysis with fluorescence detection. Results: Urinary concentrations were $107 \%$ higher in firefighters that were recently involved in firefighting activities comparatively with the control Group ( 0.058 versus $0.028 \mu \mathrm{mol} / \mathrm{mol}$ creatinine), respectively. Median concentrations of urinary 1 - hydroxypyrene were below the benchmark level $(0.5 \mu \mathrm{mol} / \mathrm{mol}$ creatinine) proposed by American Conference of Governmental Industrial Hygienists. Conclusions: More studies including other PAH biomarkers of exposure and (bio)markers of early effect are necessary to better characterize firefighters' occupational exposure and to estimate the potential health risks.
\end{abstract}

Keywords: Occupational exposure, Firefighters, Biomarkers of exposure, PAH metabolites, 1 hydroxypyrene.

\section{INTRODUCTION}

Portugal is among the southern European countries that present the highest danger for the occurrence of large forest fires and the risk is expected to continue increasing in the next decades (San-Miguel-Ayanz et al. 2018). Forest fires release large amounts of numerous hazardous pollutants to the atmosphere, which represent serious risks for the health of exposed fire combat forces and populations (Oliveira et al., 2015a, 2015b). Firefighting activities are among the most dangerous professions and are classified as possible carcinogen to humans by the International Agency for Research on Cancer and the US National Institute for Occupational Safety and Health (IARC 2010, NIOSH, 2007). Firefighters' occupational exposure has been associated with excess morbidity and mortality, with growing evidence supporting an association with all-cause of mortality, being cardiovascular disease the leading cause of death and a major cause of their morbidity (Oliveira et al., 2015a, 2015b).During fire combat activities, firefighters are heavily exposed to several hazardous pollutants, including particulate matter, nitrogen dioxide, carbon monoxide, volatile and semi-volatile organic compounds such as polycyclic aromatic hydrocarbons, PAHs (Gianniou et al., 2016; Oliveira et al., 2017). PAHs are ubiquitous hazardous pollutants with some compounds presenting toxic, mutagenic, endocrine disrupting and carcinogenic properties (IARC 2002, 2010; Oliveira et al., 2017; WHO, 2013). PAHs are also known to cause reproductive, developmental, cardiorespiratory, and immune toxic effects in humans (Oliveira et al., 2019). Firefighters are exposed to PAHs through the inhalation of gases, smoke and dusts released during fires, as well as through dermal exposure (Oliveira et al., 2015-PAHs). PAHs are absorbed into the human body and are distributed to the lypophilic tissues. Metabolization occurs via oxidative pathways in the liver to expedite their excretion from the human body in the form of glutathione, glucuronide, and sulphate conjugates through the urine, milk, and feces (Oliveira et al., 2019). However special attention has been given to urine since it is the easiest, cheapest, and less invasive matrix, which is particularly important for occupationally exposed groups. Regular exposure to health-relevant pollutants may induce 
the generation of reactive species that will promote and/or aggravate pulmonary and cardiovascular inflammatory processes (Gianniou et al., 2016). Therefore, human biomonitoring is a precious tool to estimate the effective and total personal exposure to a specific pollutant, regardless of the route and duration of exposure (Oliveira et al., 2017, 2019). Among the available PAH biomarkers of exposure, 1-hydroxypyrene is the most widely used biological indicator of internal dose of PAHs exposure (Jongeneelen, 2014). This study determines firefighters' occupational exposure to PAHs, through the determination of urinary 1hydroxypyrene, the PAHs biomarker of exposure, before and immediately after firefighting activities.

\section{METHODOLOGY}

Forty-two firefighters serving at different fire stations situated in the district of Bragança (North of Portugal) fulfilled a questionnaire to collect data on their demographic characteristics (gender, age, and weight), and factors associated with PAH exposures including tobacco consumption, the most consumed meals (boiled, grilled, roasted), and recent exposure to fire emissions during the 2-3 days before sampling campaign. Participants signed a previously validated and approved informed consent (Ethic Committee of University of Porto; 12/CEUP/2015) and collected a spot urine sample at the end of their work-shift. Urine samples were collected in sterilized polycarbonatecontainers and frozen at $-20^{\circ} \mathrm{C}$ until analysis. Subjects were divided into two different groups: non-smoking and non-exposed to fire emissions (control group) and non-smoking and exposed to fires subjects. Urinary 1-hydroxypyrene was exctrated and quantified according to Oliveira et al. (2017). Urinary extracts were analysed using a Shimadzu LC system (Shimadzu Corpora-tion, Kyoto, Japan) equipped with a fluorescence detector in a C18 column (CC 150/4 Nucleosil 100-5C18PAH, $150 \times 4.0 \mathrm{~mm} ; 5 \mu \mathrm{m}$ particle size; Macherey-Nagel, Duren,Germany) at room temperature (20 $\left.\pm 1{ }^{\circ} \mathrm{C}\right)$. 1-hydroxypyrene was detected at its optimum excitation/emission wavelength pair (242/388 nm), Urinary levels of creatinine were determined by the Jaffe colorimetric method (Kanagasabapathy and Kumari, 2000) and used to normalize the concentrations of 1-hydroxypyrene. Analytical blanks and standards were analysed daily and regu-larly. Each analysis was performed at least in triplicate. Statistical analysis was done using SPSS (IBM SPSS Statistics 20) and Statistica software (v. 7, StatSoft Inc., USA). Levels of 1-hydroxypyrene were expressed as median values, compared through the nonparametric Mann-Whitney $U$ test and statistical significance was defined as $p \leq$ 0.05 .

\section{RESULTS AND DISCUSSION}

The firefighters that agreed to voluntary participate in this study were all healthy (nonchronically diagnosed diseases) and non-smoking subjects with a mean age of 34 years (22-48 years). The time dedicated to firefighting activities within the $48 \mathrm{~h}$ prior the urine sampling collection varied between 1 to 8 hours. Urinary 1-hydroxypyrene was detected in all the exposed firefighters, and in $96 \%$ of the non-exposed individuals, thus reflecting its adequacy to evaluate occupational exposure to PAHs. Limited information is available concerning the elimination kinetics of urinary 1-hydroxypyrene, with half-life excretion rates ranging between $6-35 \mathrm{~h}$ after inhalation exposure (Brzeznicki et al., 1997; Jongeneelen et al., 1990), 4-12 h after ingestion (Li et al., 2012), and reaches $13 \mathrm{~h}$ for dermal adsorption (Sobus et al., 2009; Viauet al., 1995; Viau and Vyskocil, 1995). Urinary 1-hydroxypyrene concentrations were $107 \%$ higher in non-smoking subjects (median $0.058 \mu \mathrm{mol} / \mathrm{mol}$ creatinine; range: $0.019-0.193 \mu \mathrm{mol} / \mathrm{mol}$ creatinine) that were directly involved in firefighting comparatively with non-smoking and non-exposed subjects 
(median $0.028 \mu \mathrm{mol} / \mathrm{mol}$ creatinine; range: $0.002-0.230 \mu \mathrm{mol} / \mathrm{mol}$ creatinine). Studies regarding firefighters' occupational exposure to PAHs are limited. However, urinary levels of 1hydroxypyrene in Portuguese firefighters were lower than the values reported by other authors for firefighters (Laitinen et al., 2010) and other occupationally exposed groups such as metallurgy, coke oven, and bitumen workers (Barbeau et al., 2014; Campo et al., 2012; Lotz et al., 2016). There are no guidelines for biomonitoring occupational exposure to PAHs in Europe. However, concentrations of 1-hydroxypyrene were always below the benchmark level of 0.5 $\mu \mathrm{mol} / \mathrm{mol}$ creatinine, proposed by the American Conference of Governmental Industrial Hygienists (ACGIH, 2010) and the no-biological effect level for occupational exposed workers $(1.4 \mu \mathrm{mol} / \mathrm{mol}$ creatinine) proposed by Jongeneelen (2014). Therefore, firefighters' occupational exposure to PAHs do not represent potential health hazards. Since firefighting is an intermittent occupation, firefighters' occupational exposure is directly related with the number of fire occurrences and the time spent with fire suppression. Therefore, firefighters' total internal dose of PAHs is expected to vary widely during the season of forest fires.

\section{CONCLUSIONS}

This work characterized firefighters' occupational exposure to PAHs during their work shift after their active participation in firefighting activities. Firefighters that were actively involved in firefighting activities presented higher urinary concentrations of 1-hydroxypyrene than the subjects from the control group. More comprehensive studies during larger periods of time and including other PAH biomarkers of exposure are needed in a larger group of subjects to validate these findings.

\section{Acknowledgments}

This work received financial support by projects UID/QUI/50006/2019 and UID/EQU/00511/2019 Laboratory for Process Engineering, Environment, Biotechnology and Energy - LEPABE funded by national funds through FCT/MCTES. M. Oliveira thanks to FCT/MCTES for the CEEC- Individual 2017 Program Contract: CEECIND/03666/2017. Authors are thankful for the cooperation with Escola Superior de Saúde - Instituto Politécnico de Bragança and to all participants.

\section{References}

ACGIH. 2010. "Documentation for a Recommended BEI of Polycyclic Aromatic Hydrocarbons". American Conference of Governmental Industrial Hygienists, Cincinatti, Ohio, USA.

Barbeau, D., R. Persoons, M. Marques, C. Herve, G. Laffitte-Rigaud, A. Maitre. 2014. "Relevance of urinary 3hydroxybenzo(a) pyrene and 1-hydroxypyrene toassess exposure to carcinogenic polycyclic aromatic hydrocarbon mixtures in metallurgy workers". Ann. Occup. Hyg. 58: 579-590.

Brzeznicki, S., M. Jakubowski, B. Czerski, 1997. "Elimination of 1-hydroxypyreneafter human volunteer exposure to polycyclic aromatic hydrocarbons”. Int.Arch. Occup. Environ. Health 70: 257-260.

Campo, L., L. Vimercati, A. Carrus, L. Bisceglia, A.C. Pesatori, P.A. Bertazzi, et al., 2012. “Environmental and biological monitoring of PAHs exposure in coke-oven workers at the Taranto plant compared to two groups from the general population of Apulia, Italy". Med. Lav. 103(5): 347-360.

Gianniou, N., P. Katsaounou, E. Dima, C-E. Giannakopoulou, M. Kardara, V. Saltagianni, et al. 2016. "Prolonged occupational exposure leads to allergic airway sensitization and chronic airway and systemic inflammation in professional firefighters". Resp. Med. 118: 7-14. DOI: doi: 10.1016/j.rmed.2016.07.006.

IARC Working Group on the Evaluation of Carcinogenic Risks to Humans. 2002. "Some traditional herbal medicines, some mycotoxins, naphthalene and styrene". IARC Monogr. Eval. Carcinog. Risks Hum. 82: 1-556. 
IARC Monographs on the Evaluation of Carcinogenic Risks to Humans. 2010a. "Painting, Firefighting and Shiftwork". 98. International Agency for Research on Cancer, Lyon, France.

IARC Working Group on the Evaluation of Carcinogenic Risks to Humans. 2010b. "Some non-heterocyclic polycyclic aromatic hydrocarbons and some related exposures". IARC Monogr. Eval. Carcinog. Risks Hum. 92: 1-853.

Jongeneelen, F.J. 2014. "A guidance value of 1-hydroxypyrene in urine in view ofacceptable occupational exposure to polycyclic aromatic hydrocarbons".Toxicol. Lett. 231: 239-248.

Jongeneelen, F.J., F.E. Van Leeuwen, S. Oosterink, R.B. Anzion, L.F. van Der, R.P. Bos, et al. 1990. “Ambient and biological monitoring of cokeovenworkers: determinants of the internal dose of polycyclic aromatichydrocarbons". Br. J. Ind. Med. 47: 454-461.

Kanagasabapathy, A.S., S. Kumari. 2000. "Guidelines on Standard Operating Procedures for Clinical Chemistry". World Health Organization, New Delhi, 25-28.

Laitinen, J., M. Mäkelä, J. Mikkola, I. Huttu. 2010. “Fire fighting trainers' exposure tocarcinogenic agents in smoke diving simulators". Toxicol. Lett. 192: 61-65.

Li, Z., L. Romanoff, S. Bartell, E.N. Pittman, D.A. Trinidad, M. McClean, et al. 2012. "Excretion profiles and half-lives of ten urinary polycyclic aromatic hydrocarbon metabolites after dietary exposure". Chem. Res. Toxicol. 25: 1452-1461.

Lotz, A., B. Pesch, G. Dettbarn, M. Raulf, P. Welge, H-P. Ribs, et al. 2016. "Metabolites of the PAH diol epoxide pathway and other urinary biomarkers of phenanthrene and pyrene in workers with and without exposure to bitumen fumes". Int. Arch. Occup. Environ. Health 89: 1251-1267.

Oliveira, M., K. Slezakova, M.J. Alves, A. Fernandes, J.P. Teixeira, C. Delerue-Matos, et al.

2017. "Polycyclic aromatic hydrocarbons at fire stations: firefighters' exposure monitoring and biomonitoring, and assessment of the contribution to total internal dose". J. Hazard. Mater. 323: 184-194.

Oliveira, M., K. Slezakova, C. Delerue-Matos, M.C. Pereira, S. Morais. 2019. “Children environmental exposure to particulate matter and polycyclic aromatic hydrocarbons and biomonitoring in school environments: A review on indoor and outdoor exposure levels, major sources and health impacts". Environment International 124: 180-204.

Oliveira, M., K. Slezakova, C. Delerue-Matos, M.C. Pereira, S. Morais. 2017. "Firefighter's occupational exposure: Review on air pollutant levels and potential health effects". In: B. R. Gurjar, P. Kumar, and J N Govil (Eds) Multi. Vol set on Environmental Science and Engineering (in 12 vols set), Vol. 3: Air and Noise Pollution, Studium Press LLC, Houston, USA: 63-91.

Oliveira, M., K. Slezakova, C. Delerue-Matos, M.C. Pereira, S. Morais. 2015. "Polycyclic aromatic hydrocarbon emissions from forest fires: assessment of firefighters' exposure" In: Boone C (Ed). Polycyclic Aromatic Hydrocarbons, Series: Environmental Science, Engineering and Technology, Hauppauge, New York, USA: Nova Science Publishers, 59-94.

NIOSH. 2007. "NIOSH Pocket Guide to Chemical Hazards". U.S. Department of Healthand Human Services, Public Health Service, Centers for Disease Control andPrevention. National Institute for Occupational Safety and Health, Cincinnati,Ohio.

San-Miguel-Ayanz, J., T. Durrant, R. Boca, G. Libertà, A. Branco, D. de Rigo, et al. 2018. "Forest Fires in Europe, Middle East and North Africa 2017". EUR 29318 EN.

Sobus, J.R., M.D. McClean, R.F. Herrick, S. Waidyanatha, F. Onyemauwa, L.L. Kupper, et al. 2009. "Investigation of PAH biomarkers in the urine of workersexposed to hot asphalt". Ann. Occup. Hyg. 53: 551-560.

Viau, C., A. Vyskocil, 1995. "Patterns of 1-hydroxypyrene excretion in volunteersexposed to pyrene by the dermal route". Sci. Total Environ. 163: 187-190.

Viau, C., G. Carrier, A. Vyskocil, C. Dodd. 1995. "Urinary excretion kinetics of 1-hydroxypyrene in volunteers exposed to pyrene by the oral and dermalroute". Sci. Total Environ. 163: 179-186.

WHO. 2013. "State of the Science of Endocrine Disrupting Chemicals 2012". United Nations Environment Programme and the World Health Organization, Geneva. 